\title{
Recognition of affixed words and the word frequency effect
}

\author{
MARCUS TAFT \\ Monash University, Clayton, Victoria 3168, Australia
}

\begin{abstract}
Three experiments are reported in which the word frequency effect is used as a diagnostic for determining whether affixed words coming from the same stem are stored together or separately in the lexicon. Prefixed words are examined in the first experiment, inflected words in the second and third. In the first two experiments, two types of word are compared where the words in each condition are matched on surface or presented frequency but are varied on the frequency of their stems or base frequency. It is found that lexical decision times are influenced by base frequency, thus indicating that words related by affixation are stored together in the lexicon. The third experiment, however, demonstrates that when base frequency is held constant and surface frequency is varied, lexical decision times are influenced by surface frequency. The results are accounted for by a model of word recognition whereby frequency has its effect at two different stages of the recognition process.
\end{abstract}

In a paper by Taft and Forster (1975), evidence was presented to support the view that visually presented prefixed words are analyzed into their separate morphemes (prefix and stem) when they are to be recognized. For example, the recognition of the word "unhook" would involve the stripping off of the prefix "un" and the subsequent location of the lexical entry for "hook." That is, "hook" and "unhook" would be accessed through the same lexical entry. The results obtained by Taft and Forster implied, furthermore, that a prefixed word is accessed via its stem even when this stem is not a word in its own right (as "hook" is). For example, the prefixed word "persuade" would be recognized after the prefix "per" was stripped off and the stem "suade" was located in the lexicon. Thus, it is claimed that the nonword "suade" is stored in the lexicon for the purpose of recognizing "persuade." It would also be stored for the purpose of recognizing "dissuade." Does this mean, then, that "persuade" and "dissuade" are accessed through the same lexical entry, "suade," or are there two separate entries for "suade"? This is the question that will be addressed in the first experiment to be reported.

The idea behind this experiment is similar to that of Rosenberg, Coyle, and Porter (1966), as well as Experiment 5 of Taft and Forster (1976). Rosenberg et al. employed a free recall task for lists of adverbs that were derived either from common adjectives (e.g., brightly) or uncommon adjectives (e.g., briskly). These two types of item were equated for frequency of occurrence of their adverbial forms, that is, the form in which the words were presented. It was found that the zase of recall of the adverbs was influenced by the frequency of their adjectival stems. Thus, "brightly" was presumably encoded in this episodic task as "bright," and "briskly" as "brisk."

The frequency effect was similarly employed by
Taft and Forster (1976), but this time, the task was a lexical one rather than an episodic one. In addition, compound words were examined rather than derived adverbs. The proposal being tested was that compound words are accessed through their first constituent morphemes. To this end, two sets of compound words were selected wherein one set of the words contained high-frequency first constituents (e.g., headstand), while in the other, the words contained low-frequency first constituents (e.g., loincloth). The two sets were matched for frequency of the words as a whole, as well as frequency of their second constituent morphemes. It was found that the former type of item was classified as a word faster than the latter type, thus indicating that the frequency of the first constituent was indeed important. It appeared, therefore, that "headstand" was recognized via the lexical entry "head," and "loincloth" via "loin."

The first experiment to be reported here uses the frequency effect as a diagnostic for determining whether prefixed words coming from the same nonword stem (e.g., "suade") are stored together or separately in the lexicon. Before the details of this experiment are elaborated upon, however, a more extensive description of the word frequency effect in lexical recognition will be presented.

The word frequency effect, where words of high frequency in the language are more readily recognized than words of low frequency, is one of the most robust findings in visual word recognition experiments. To explain the effect, Broadbent (1967) supports a model whereby the recognition system is biased toward encountering high-frequency words before low-frequency words in the accessing process. There have been two major models of this type that have been put forward: the ordered search model (Forster, 1976; Forster \& Bednall, 1976; Rubenstein, Garfield, \& Millikan, 1970; 
Taft \& Forster, 1975) and the logogen model (Morton, 1968, 1969).

According to the ordered search model, lexical representations are listed in order of frequency of occurrence, highest at the beginning, lowest at the end. A search made for a lexical item proceeds through this ordered list from the beginning, and thus high-frequency words are encountered before low-frequency words.

The logogen model is a passive model of word recognition. The information level of each lexical entry, or logogen, is raised when the sensory input contains appropriate features. When the level of information passes a threshold value in any logogen, the word that corresponds to that particular logogen becomes available for recognition. Over time, the level drops back to its original "resting" state. The resting level is dependent upon frequency of occurrence. High-frequency words have a higher resting level than low-frequency words so that they reach the threshold level more quickly (if they also have the appropriate features). In this way, the higher the frequency of a word, the more readily that word is recognized.

In describing the present set of experiments, the ordered search model will be adopted for ease of explanation. However, the implications of the results for the logogen model will be discussed in some detail later.

\section{EXPERIMENT 1}

Experiment 1 exploits the frequency effect in order to test whether prefixed words with the same stem are stored together or separately. If "persuade" and "dissuade" are accessed through the same single entry (i.e., "suade"), then the positioning of that entry in the lexicon will be dependent upon the combined frequencies of "persuade" and "dissuade" (i.e., the frequency of "suade"). Similarly, the positioning of the entry "proach" will be dependent upon the frequencies of both "approach" and "reproach." Both "reproach" and "dissuade" have a frequency value of 3 (according to Kucera \& Francis, 1967), but "approach" has a frequency value of 123 , while "persuade" has a frequency value of only 17 . Thus "proach" has a higher frequency than "suade" (i.e., 126 vs. 20). If this is so, then "reproach" should be recognized more quickly as a word than "dissuade," since the stem of the former is of higher frequency. Figure 1 illustrates this prediction. The recognition of both "reproach" and "dissuade" will involve the following steps: The prefix will be stripped off, the lexical entry for the stem will be located, the higher frequency word with the same root will be examined and rejected, and finally, the lower frequency word with the same root will be examined and accepted. The difference between "reproach" and "dissuade" will occur at the stage when the lexical entry for the stem is located. Since "proach" is of higher frequency than "suade," it will be located more quickly than "suade."

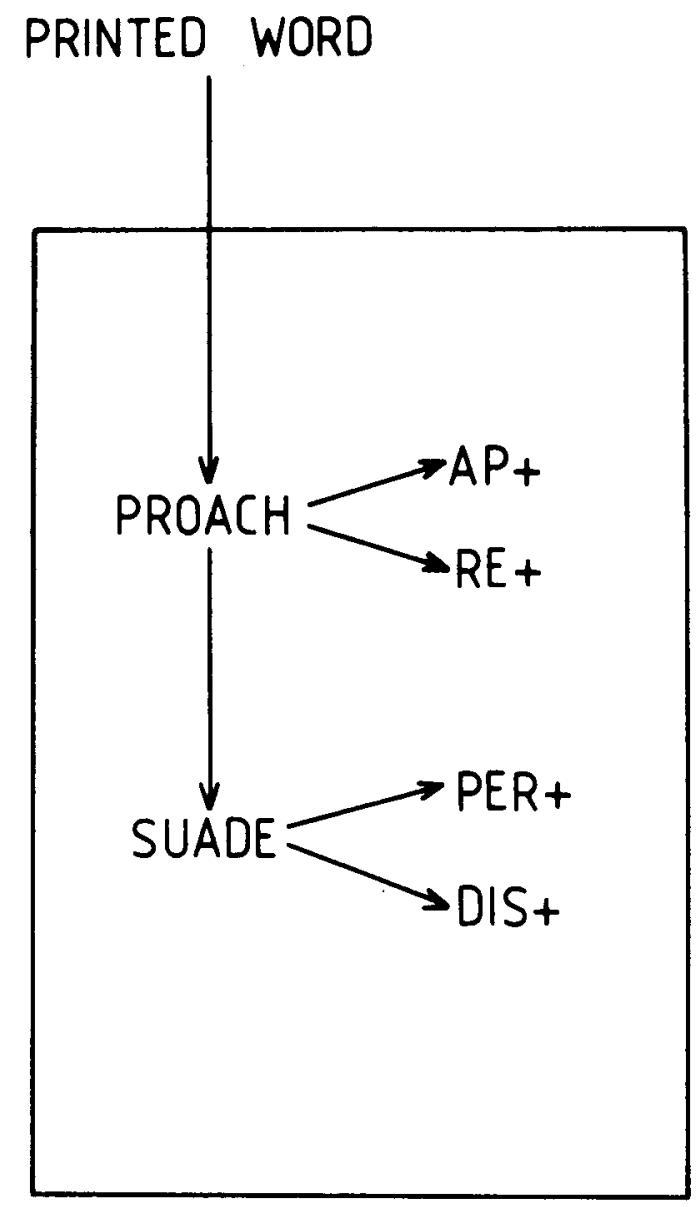

Figure 1. Model of the lexicon where words coming from the same stem are accessed through the same entry.

If, on the other hand, words of the same stem are stored separately, then the positioning of the entry for "reproach" (i.e., "proach") will be based upon the frequency of "reproach" only, and the positioning of the entry for "dissuade" (i.e., "suade") will be based solely on the frequency of "dissuade." Since "reproach" and "dissuade" have the same frequency, they will be listed in approximately the same place. This is illustrated in Figure 2. The recognition of both "reproach" and "dissuade" will involve the following steps: The prefix will be stripped off, the first representation of the stem will be located, this entry will be found to be inappropriate after further examination, the search will continue, and finally, the appropriate representation of the stem will be accessed. The appropriate entry for "reproach" will be found in approximately the same time as the appropriate entry for "dissuade." In both cases there will be one interfering entry, but the point at which this interference occurs will not affect reaction times, since the search must continue to the same point in both cases. Therefore, if words coming from the same stem are stored separately, there should be no difference between the recognition time for "reproach" and the recognition time for "dissuade."

To summarize the predictions: If words related by the same stem are accessed through the same lexical 


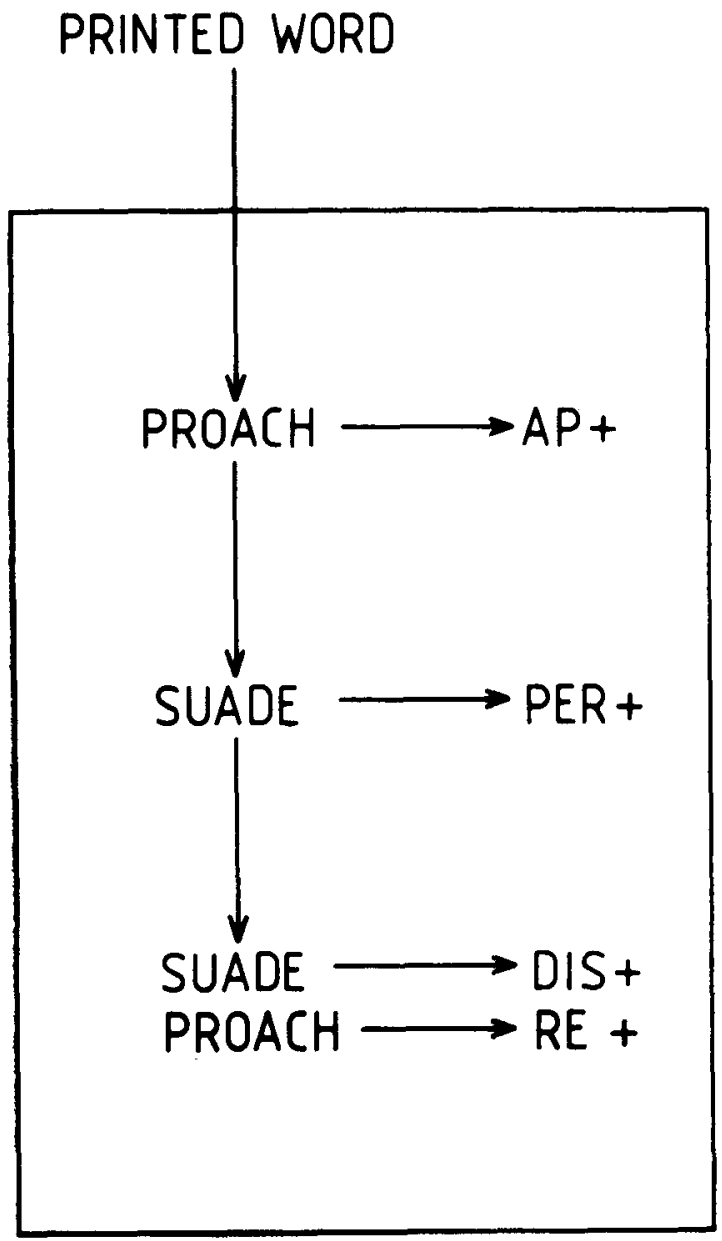

Figure 2. Model of the lexicon where words coming from the same stem are accessed through different entries.

entry, then the frequency of a prefixed word (e.g., approach) will be reflected in the reaction time to a lower frequency prefixed word that comes from the same root (e.g., reproach). If words related by the same stem are accessed through separate lexical entries, then the frequency of a prefixed word will not affect the reaction time to a lower frequency prefixed word that comes from the same stem.

\footnotetext{
Method

Materials. Items were designed in pairs. Eighteen words with a high-frequency stem (HFS condition; e.g., reproach) were paired with 18 words with a low-frequency stem (LFS condition e.g., dissuade). Pairs were matched both on frequency of the word as a whole and on the number of words that came from the same root and were of higher frequency than the word presented (e.g., for both "reproach" and "dissuade," there is only one word of higher frequency that comes from the same root, "approach" and "persuade," respectively ${ }^{1}$ ). Matching on the second variable was necessary in order to equate the two conditions on the number of possible interfering entries in each case. The mean stem frequency of the HFS condition words was 100 , and the mean stem frequency of the LFS condition words was 14. The 36 experimental items (given in the Appendix) were randomly presented together with 35 similarly prefixed nonwords as distractor items. Ten practice items were given.
}

Procedure. A lexical decision task was employed whereby subjects were to classify items as words or nonwords. Items were typed on cards in lowercase and presented on a two-field tachistoscope for an exposure period of $500 \mathrm{msec}$. Subjects responded by saying "yes" into a microphone when they recognized the item as a word and "no" when they recognized it as a nonword. The timing mechanism was triggered by the onset of the stimulus presentation and stopped by the onset of the vocal response. The intertrial interval was approximately $5 \mathrm{sec}$, with the experimenter saying "ready" prior to the presentation of each stimulus item. The items were presented in a different order for each subject. There were 20 subjects used.

\section{Results and Discussion}

Table 1 presents the item means for the two experimental conditions. A comparison of the two conditions revealed a significant difference $\left[\min \mathrm{F}^{\prime}(1,37)=6.07\right.$, $\mathrm{p}<.02]$, with the HFS condition items being more quickly recognized than LFS condition items. Although there was a negative correlation between error rate and reaction time, there was no evidence to suggest that this was a result of a speed-accuracy tradeoff, since the error difference was by no means significant $\left(\min \mathrm{F}^{\prime}<1\right)$.

That the frequency of a word can influence the response times to a lower frequency word coming from the same stem is explainable in terms of a model in which the words are accessed through the same entry (Figure 1). If words with the same stem were accessed through separate entries (Figure 2), then it would be very difficult to explain why reaction times to the words in the two conditions, matched on overall frequency, could differ from each other.

There is, however, a potential problem with the experiment that would jeopardize its validity. This is the problem of regression toward the mean. In any tabulation of word frequencies (e.g., Kučera \& Francis), there must be words that have been accidentally overand underestimated through sampling error. When two samples of items are selected so that they are matched on word frequency but differ on another variable (e.g., length), the inaccuracy in the word frequency count normally should not systematically influence the results, since the two samples should be affected to the same extent. However, if the variable on which the two samples differ is highly correlated with word frequency, then it is possible that the over- or underestimation of frequency is systematically different between the two samples. In the present experiment, the variable on which the two samples differ is stem frequency, and this may well be correlated with word frequency in the

Table 1

Mean Reaction Times (in Milliseconds), Standard Errors, and Percentage Error Rates for the HFS and LFS Conditions

\begin{tabular}{ccccc} 
Condition & Example & $\begin{array}{c}\text { Reaction } \\
\text { Time }\end{array}$ & $\begin{array}{c}\text { Standard } \\
\text { Error }\end{array}$ & $\begin{array}{c}\text { Percent } \\
\text { Error }\end{array}$ \\
\hline HFS & Reproach & 747 & 12 & 6 \\
LFS & Dissuade & 794 & 15 & 4 \\
\hline
\end{tabular}


population of words. When selecting the two samples of items, matching them on word frequency so that one sample has a low stem frequency relative to the other, it may be the case that the only available items with a relatively low stem frequency are those whose word frequency is underestimated in the word count. If this were so, not only would the HFS words have higher stem frequencies than LFS words, but they would also be more common as words. In order to determine whether or not the results obtained were in fact a regression artifact, a second word frequency count was inspected. It would be most unlikely that exactly the same sampling errors would have been committed in two independent word counts. To this end, the word frequency count of Thorndike and Lorge (1944) was employed to determine the frequencies of items used in the experiment. A logarithmic conversion was made of the frequency values given, since reaction time appears to be a function of $\log$ frequency rather than of frequency per se (e.g., Swift, 1977). From this analysis it was found that the HFS words were indeed well matched on frequency with the LFS words, there being no difference at all between their frequencies $[\mathrm{t}(17)=.35, \mathrm{p}>.05]$.

The results of this experiment, then, clearly confirm the conclusions drawn by Taft and Forster (1975) that prefixed words are decomposed morphologically for recognition and also that nonword stems are represented in the lexicon. The frequency of the nonword stems of the words used in the present experiment would not have been relevant to recognition times had those words not been analyzed into prefix plus nonword stem, and had these nonword stems not been stored in the lexicon.

The possible effect on recognition times of the frequency of prefixed word stems has been used by Manelis and Tharp (1977) to, in fact, dispute the conclusions drawn by Taft and Forster (1975). Taft and Forster base their conclusion that nonword stems have lexical status on the finding that lexical decision times to nonwords that are stems of prefixed words (e.g., "vive" from "revive") are longer than those to nonwords that are parts of, but not stems of, nonprefixed words (e.g., "lish" from "relish"). Thus it is supposed that "vive" is actually represented in the lexicon, leading to a delay in nonword decision times. In designing the items for this experiment, matching was based upon the frequency of the word from which the item was derived (e.g., "revive" is the same frequency as "relish"). However, there are other words containing "vive" (e.g., survive), as well as other words containing "lish" (e.g., polish). Manelis and Tharp point out that the mean frequency in the Taft and Forster (1975) experiment for all the words that contain items like "vive" (i.e., revive + survive + survival, etc.) was greater than that for all the words that contain items like "lish." That is, the "vive"-type items were more common in English than the "lish"-type items. From this, Manelis and Tharp propose that it is possibly only higher frequency word fragments that are stored in the lexicon, and it may be that their morphological status is irrelevant. Thus Manelis and Tharp do not dispute that prefixed words are decomposed for recognition into fragments, but they do suggest that these fragments need not be morphemes, just commonly occurring fragments.

A major argument against this view is that, despite an overall frequency bias in favor of "vive"-type items, there were nevertheless several pairs that did not have such a bias. There is no evidence in the data presented by Taft and Forster (1975) to suggest that these items behaved any differently to biased item pairs. Examples of such pairs that were unbiased or biased in the reverse direction (along with lexical decision times) were "nihilate" (794 msec) vs. "tagonize" (693 msec), "bezzle" (772 msec) vs. "igrate" (673 msec), "whelm" (972 msec) vs. "tures" (697 msec), and "pudent" (741 msec) vs. "becile" (705 msec). Thus the "vive". type items (e.g., "nihilate") seemed to be associated with longer reaction times than "lish"-type items (e.g., "tagonize"), even when there was no frequency bias.

Manelis and Tharp (1969) do concede that it is possible that morphological analysis takes place in the recognition of prefixed words, but they present two experiments that they claim are in opposition to the idea that morphological analysis takes place in the recognition of suffixed words. Their evidence for this, however, is by no means conclusive. Since the next experiment to be reported here examines the issue of morphological analysis in the recognition of suffixed words, a more detailed evaluation of the Manelis and Tharp study will be given.

In their first experiment, Manelis and Tharp (1977) employed the double lexical decision task,- where subjects were presented with two items and had to decide whether both were words or one was a nonword. Two types of word items were used: suffixed words (e.g., tester, milky) and nonsuffixed words of the same structure (e.g., sister, candy). If morphological decomposition is undertaken in word recognition, then "sister" should be incorrectly analyzed as being "more sist" or "someone who sists" and thus the nonsuffixed items should take longer to recognize than the suffixed items. However, Manelis and Tharp failed to find any difference in the response times to two nonsuffixed words (e.g., sister somber) compared to two suffixed words (e.g., tester sender), although both of these conditions led to shorter response times than when a suffixed and a nonsuffixed word were combined (e.g., tester somber).

These results, however, are not conclusively in favor of a nondecomposition hypothesis (single-unit hypothesis). The finding that the mixed condition was more difficult than the unmixed conditions seems, in fact, to be more in favor of a decomposition hypothesis than a single-unit hypothesis. When the identical letter grouping (e.g., "er") has a different morphological function in each member of an item pair, this conflict 
could increase recognition times, but only if the words are morphologically analyzed. Manelis and Tharp (1977) attempt to explain this result quite differently, in terms of semantic relatedness (cf. Meyer \& Schvaneveldt, 1971). They claim that part of the meaning of a word is conveyed by its affix and so if two words are affixed in the same way, they will be somewhat semantically related. Thus "tester" and "sender" both have as part of their meanings "someone who performs a particular action," and it is this meaning relationship between the two words that leads to faster recognition times than in the mixed condition. This explanation is quite feasible for the suffixed words, but it is difficult to see how it can be generalized to the nonsuffixed word pairs. The "er" ending of "sister" and "somber" clearly contributes no independent meaning to those words (unlike the "er" of "tester"), so how can "sister" and "somber" be in any way semantically related, other than by chance?

The failure to find any difference between the two unmixed conditions is also not entirely convincing. Seven of the 15 item sets contained an "er" agentive suffix (e.g., tester) or an "en" adjectival suffix (e.g., waxen). The "er" suffix is, however, more commonly found in English as a comparative inflection (e.g., later), and the "en" suffix as a participial inflection (e.g., given). Thus items like "tester" are just as likely to be incorrectly treated as "more test" as items like "sister" are to be incorrectly treated as "more sist."

The results obtained by Manelis and Tharp (1977) for nonwords are, in fact, in favor of a morphological decomposition hypothesis also. It was found that suffixed nonwords whose "stems" were words (e.g., "desker") took longer to classify as nonwords than those whose stems were not words (e.g., "losker"). Nonwords whose stems were the first part of a word (e.g., "garmer" from "garment") behaved exactly like the "desker"-type items. Clearly, the components within the items influenced recognition times, and this implies that the nonwords were analyzed into their potential norphemes.

The similarity of items like "desker" with items like "garmer" in fact supports the conclusions of Taft and Forster (1976). These authors claim that words are represented in the lexicon in terms of the first syllable, or, more precisely, the basic orthographic syllabic structure, or BOSS (Taft, 1979). The BOSS is the first ;yllable of a word defined orthographically and morphoogically. The BOSS of a monosyllabic word (e.g., desk) $s$ the word itself and the BOSS of "garment" is "garm" ind, therefore, "desk" and "garm" should have the same exical status. Since nearly all the stems of the "garmer"ype items used by Manelis and Tharp (1977) were 3OSSs, the finding that "garmer" led to as much nterference in response times as "desker" is support for he BOSS storage view.

Manelis and Tharp (1977) ran a second experiment hat they also believed was in support of the single-unit hypothesis. Subjects were presented with a word (e.g., snow), and this was then followed by a suffixed word or a suffixed nonword. The task was to say whether the initially presented word was contained in the item that followed (e.g., "yes" for "snowed" and "snowen," "no" for "slowed" and "slowen"). It was found that the base word took longer to recognize in a nonword than in a word. Manelis and Tharp argued that if morphological decomposition is carried out in word recognition, then subjects should have found "snow" in "snowen" as quickly as they found "snow" in "snowed," since decomposition must occur prior to lexical access. There is, however, a major problem with the materials used in this experiment that greatly weakens the finding of the word-nonword difference. The distribution of suffixes that were added to make up the word items was very different from that added to make up the nonword items. The very common suffixes "ing," "ed," and "er" occurred in 80 of the 96 word stimuli but in none of the nonword stimuli. On the other hand, the far rarer suffixes "es" (inappropriately used), "est," and "en" occurred in 62 of the 96 nonword stimuli but in none of the word stimuli. This imbalance in the frequencies of the suffixes used may have led to the longer reaction times to nonwords. In order for a suffix to be stripped off, it must be recognized as being a suffix, presumably from some lexical listing. It is not at all unreasonable to suggest that suffix frequency may affect such recognition of suffixes.

In summary, then, it would seem that Manelis and Tharp (1977) have not provided convincing evidence against the notion that morphological decomposition takes place in word recognition. The second experiment to be reported here examined the issue of morphological analysis in the recognition of inflected words in order to provide further evidence for or against the decomposition hypothesis. Like Experiment 1, the second experiment exploits the frequency effect in order to test whether words coming from the same stem are stored together or not. In this case, however, the stems are always words themselves (e.g., the "like" of "likes," "liking," "liked").

\section{EXPERIMENT 2}

If an inflected word (e.g., likes) were recognized by stripping off the suffix "s" and by then locating the lexical entry for its stem (like), then there would be no lexical entry represented as the inflected word (likes). Rather, "likes," "liking," and "liked" would all be accessed through a single entry, namely, "like." The effect of this on frequency would be that the frequency of the lexical entry "like" would be the summed frequency of "like," "likes," "liking," and "liked." This is the single-entry model and is represented in Figure 1.

The separate-entry model, as exemplified by Figure 2 or by the single-unit hypothesis of Manelis and Tharp 
(1977), would say that "like," "likes," "liking," and "liked" are accessed through separate lexical entries. According to this model, the frequency influencing the recognition time to "likes" will be the frequency of "likes" alone, and the frequency influencing recognition time to "like" will be the frequency of "like" alone.

Experiment 2 was, like Experiment 1, an examination of the influence on lexical decision times of the summed frequencies of related forms; what I will call the base frequency. Items were designed in pairs, the members of each pair being matched on surface frequency, that is, the frequency of the actual form presented. For example, the words "sized" and "raked" both have a frequency of 4 according to Kučera and Francis (1967) and constitute a matched pair. However, the base frequency of the two words of a pair differed markedly. The frequency of "sized" + "size" + "sizes" + "sizing" is 154 , while the frequency of "raked" + "rake" + "rakes" + "raking" is only 15 . Therefore, if the singleentry model is correct, words like "sized" should be recognized more quickly than words like "raked," since base frequency should influence lexical decision times. If, however, the separate-entries model or single-unit hypothesis is correct, there should be no difference in response times to "sized" and "raked," since they are matched on surface frequency.

A similar experiment to this has been previously reported by Reisner (1972). She found that the base frequency of inflected words did affect reaction times. However, Reisner's results are suspect due to the fact that the min $F^{\prime}$ statistic was not employed. O'Connor (1975) performed a similar experiment, but with confusing results. The complexity of his results, however, may well have been an outcome of the frequency range used. For example, $O^{\prime}$ Connor used pairs of words in which the higher base frequency was, say, 500 and the lower base frequency was, say, 300. If response times are a function of log frequency rather than frequency per se, then the frequency difference of 200 is not, in fact, a large difference. In the experiment to be reported, an attempt was made to make the base frequency differences as large as possible between the conditions.

\footnotetext{
Method

Materials. Twenty pairs of inflected words were selected, whereby the members of each pair were matched on surface frequency (according to Kučera \& Francis, 1967), but one member had a far higher base frequency than the other (e.g., "sized" and "raked"). The mean base frequency of the higher base frequency condition was 323; for the lower base frequency condition, it was 36 . In addition to these inflected words, a second condition was examined in which the words were uninflected. Again, surface frequency was held constant while base frequency was varied. For example, "parent" has a surface frequency of 15 , but a base frequency of 105 (due to the high frequency of "parents"), whereas "tennis," which has a surface frequency of 15 , has a base frequency of only 15 , too. Twenty such pairs of uninflected words were included in the experiment. The mean base frequency of the higher base frequency condition was 93 ; for the lower base frequency condition, it was 32 .
}

The 80 experimental items (listed in the Appendix) were presented randomly to 25 subjects, together with 60 nonword distractor items. Half of the nonwords were inflected (e.g., "shigs") and half were not (e.g., "wange").

Procedure. The procedure was the same as that described in Experiment 1, although this time items were presented on a video display unit controlled by a PDP-11/10 computer. Subjects were self-paced, pressing a foot switch each time they wished to receive the next item.

\section{Results and Discussion}

Table 2 presents the item means for the four word conditions. It can be seen from the table that for both inflected and uninflected words, the higher base frequency condition was faster than the lower base frequency condition. This was significant in both cases [min $\mathrm{F}^{\prime}(1,32)=8.31, \mathrm{p}<.01$ (inflected), and $\min F^{\prime}(1,28)=4.34, p<.05$ (uninflected)] .

These results appear to be in support of the decomposition hypothesis, which claims that words that come from the same stem are stored as a single lexical entry. It is difficult to see how a separate-entries model could account for the effect observed, since the actual items presented were of the same frequency across conditions.

Once again, though, an examination was made of the frequency of the words used, in order to ascertain whether or not the results stemmed from a regression artifact. It must be known whether or not the surface frequency of the high base frequency words was matched with that of the low base frequency words, using a second, independent word frequency count. For this experiment, the word count of Carroll, Davies, and Richman (1971) was employed rather than that of Thorndike and Lorge (1944), since the latter only lists base frequencies. The values used in the analysis were the logarithmic conversions of the $U$ values provided by Carroll et al., these values being comparable to those listed in Kucera and Francis (1967). For the inflected words, a slight tendency was found for the high base frequency items to have higher surface frequencies than low base frequency items, but since this was far from significant $[t(19)=1.05, p>.05]$, it would seem that the high-low base frequency difference obtained in the experiment was not simply an artifact of regression toward the mean. In only 12 of the 20 item pairs did the high base frequency words have higher surface frequencies than the low base frequency words

Table 2

Mean Reaction Times (in Milliseconds), Standard Errors, and Percentage Error Rates for the Four Conditions

\begin{tabular}{|c|c|c|c|c|}
\hline $\begin{array}{l}\text { Frequency } \\
\text { Condition }\end{array}$ & Example & $\begin{array}{c}\text { Reaction } \\
\text { Time }\end{array}$ & $\begin{array}{c}\text { Standard } \\
\text { Error }\end{array}$ & $\begin{array}{c}\text { Percent } \\
\text { Error }\end{array}$ \\
\hline \multicolumn{5}{|c|}{ Inflected } \\
\hline High & Sized & 558 & 7 & 1 \\
\hline Low & Raked & 607 & 8 & 8 \\
\hline \multicolumn{5}{|c|}{ Uninflected } \\
\hline High & Parent & 560 & 8 & 5 \\
\hline Low & Tennis & 593 & 29 & 8 \\
\hline
\end{tabular}


according to Carroll et al. For the uninflected words, however, there was a far stronger tendency for the surface frequencies of high base frequency items to be greater than those of the low base frequency items. Although this was not quite significant at the .05 level $[t(19)=1.998, \quad p<.1]$, the results obtained in Experiment 2 for uninflected words must be viewed with extreme caution.

Nevertheless, despite the doubt cast upon the results for uninflected words, the effect obtained with inflected words still remains and strongly points to the conclusion that the base frequency of a word (at least, an inflected word) influences its recognition time.

The similarity of these findings with those of Experiment 1 indicate that prefixed words and inflected words are recognized via much the same sort of process. That is, the prefix or inflection is stripped off prior to lexical search and a search is undertaken for the stem. If this is true, then it must mean that there is a preliminary stage of processing whereby both the beginning of the presented word and the end of that word are examined for the presence of an affix. After any such affixes have been stripped off, the accessing process proper begins and this, according to Taft (1979) and Taft and Forster (1976), is carried out on a left-to-right basis. That is, a search is made for successive letter groupings that begin with the first letter of the word (after any prefixes).

While the results and conclusions from this experiment certainly support the combined storage model of Figure 1, the picture is complicated somewhat by the third experiment to be reported.

\section{EXPERIMENT 3}

This experiment was of the same format as the last, but this time base frequency was held constant while surface frequency was varied. If words coming from the same stem are stored together in the lexicon, then one may not expect that the surface frequency would affect lexical decision times, since such words would be represented as their stems, whose frequencies would be their base frequencies.

\section{Method}

Again, 20 inflected words and 20 uninflected words were used. This time, items were designed in pairs whereby the members of each pair were matched on base frequency. However, one member of the pair was of high surface frequency, while the other was of much lower surface frequency. For example, the words "things" and "worlds" formed an inflected pair, and "tin" and "rib" formed an uninflected pair. The surface frequency of "things" is far greater than that of "worlds," yet "thing" + "things" has the same frequency as "world" + "worlds." Similarly, "tin" is more common than "rib," but "tin" + "tins" + "tinned" + "tinning" has the same frequency as "rib" + "ribs" + "ribbed" + "ribbing." The mean surface frequencies for the two frequency conditions were 92 and 5 for the inflected words, and 47 and 7 for the uninflected.

These 80 items (listed in the Appendix) were presented randomly together with 60 distractor nonword items
Table 3

Mean Reaction Times (in Milliseconds), Standard Errors, and Percentage Error Rates for the Four Conditions

\begin{tabular}{ccccc}
$\begin{array}{c}\text { Frequency } \\
\text { Condition }\end{array}$ & Example & $\begin{array}{c}\text { Reaction } \\
\text { Time }\end{array}$ & $\begin{array}{c}\text { Standard } \\
\text { Error }\end{array}$ & $\begin{array}{c}\text { Percent } \\
\text { Error }\end{array}$ \\
\hline & & Inflected & & \\
High & Things & 526 & 8 & 3 \\
Low & Worlds & 561 & 27 & 6 \\
& & Uninflected & & \\
High & Tin & 541 & 8 & 5 \\
Low & Rib & 581 & 15 & 12 \\
\hline
\end{tabular}

constructed as in Experiment 2. Fifteen subjects were tested. The procedure was the same as that used in Experiment 2.

\section{Results and Discussion}

Mean reaction times for each condition are presented in Table 3. Analysis of these data revealed that the high surface frequency words were recognized more quickly than the lower surface frequency words, both when they were inflected $\left[\min \mathrm{F}^{\prime}(1,37)=5.66, \mathrm{p}<.05\right]$ and when they were uninflected $\left[\min F^{\prime}(1,36)=4.39, p<.05\right]$.

This result taken alone would seem to lead to exactly the opposite conclusion of Experiment 2, that is, that related word forms are stored separately in the lexicon. This is because the frequency of the actually presented form of a word appears to influence reaction times.

So it can be seen that one experiment says that base frequency is important, while the other says that surface frequency is important. How can one resolve this paradox? Consider the model of word recognition put forward by Forster (1976) and supported by Taft (1979). According to this model, the lexical accessing system is conceptually divisible into two distinct stages. First, there is the "master file" or lexicon proper. This is where all information about every word is stored. In addition, there is a set of peripheral access files: orthographic, phonological, and semantic. The orthographic file is used for visually presented language, and the semantic file for speech production. Only the orthographic file will be considered here, since the experiments involve only visual word recognition. In the orthographic file are contained the representations of words that are to be matched with the physical, orthographic representations of these words if recognition is to take place. Taft (1979) proposes that the representations stored in the orthographic file are the BOSSs of words, that is, their first syllables defined orthographically and morphologically. Each of these entries in the peripheral file provides an address to an entry or entries in the master file. The best way to conceptualize this system is by analogy to a library setup. The master file can be seen as all the books in the library, containing all the information that one wants to know; the peripheral file can be seen as the author or subject index that is used to find a particular book in the library.

The question of single vs. separate entries pertains to the lexical representation that is used to match with the 
physically presented representation. That is, the question pertains to the orthographic peripheral access file. In the master file, all forms of a word must be represented in some way, since it is here that all lexical information is provided. Therefore, by definition, each word must be stored separately in some form in the master file. The peripheral file, however, need only list the stem of the word (or BOSS of the stem), since it need only list sufficient information for the correct entry to be found. In other words, the claim is being made that words are stored in their base forms in the peripheral file, but in their surface forms in the master file. In order to explain the present results, then, one must assume that frequency plays a role in two places: the peripheral file and the master file.

To take an example, if one were required to recognize the word "likes," one would strip off the final "s" and search the peripheral file for the representation "like" (actually, this representation would be "lik," according to the results of Taft, 1979). The access time for this would be influenced by the frequency of "like" + "likes" + "liked" + "liking," that is, the base frequency. The entry found for "like" would provide an address in the master file where one would then ascertain that "like" + "s" is a word. This decision would be influenced by the frequency with which "like" combined with " $\mathrm{s}$ " to form a word, namely, the surface frequency of "likes," although it is unclear at this stage exactly what might be the mechanisms involved in producing this frequency effect. From this example, it can be seen that both the base and the surface frequencies of a word can influence its recognition latency, since there is a dual locus for the word frequency effect.

The peripheral file/master file notion is represented in Figure 3. This figure is a modification of Figure 1 whereby the words "reproach" and "approach" are now represented by the same entry (proach) in the peripheral orthographic file, but differentiated in the master file. Thus the base frequency effect observed in Experiment 1 would emanate from the peripheral file, where the frequency of the stem would be of prime importance. One would expect, nevertheless, that it would be easier to recognize "approach" than "reproach," since "ap" combines with "proach" more commonly in the master file than "re" combines with "proach."

\section{GENERAL DISCUSSION}

The first two experiments reported here provide evidence for the view that prefixed and inflected words are decomposed into their morphemes when they are to be recognized. This is in opposition to the view of Manelis and Tharp (1977) that affixed words are not given a morphological analysis in word recognition. Their claim, however, that such words are stored as single units does appear to be correct to some extent,

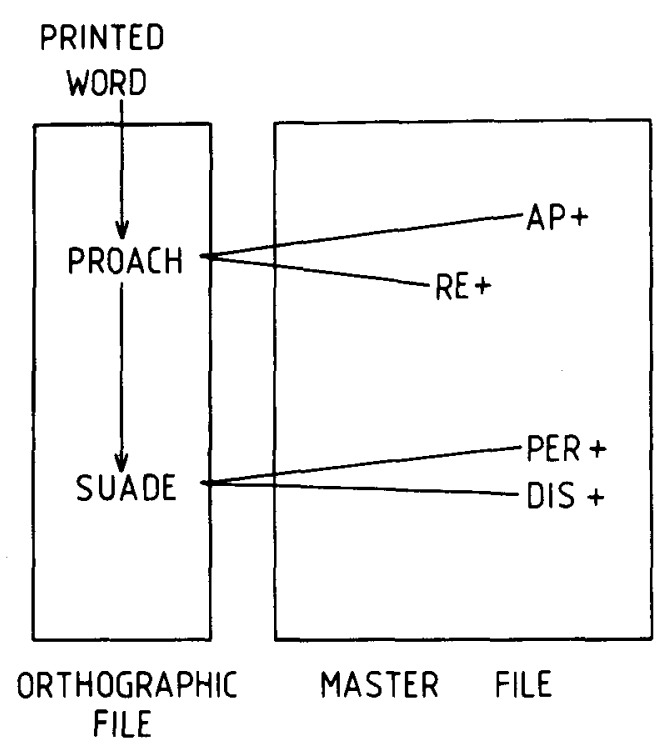

Figure 3. Peripheral file/master file model of the lexicon where words coming from the same stem are accessed through the same entry.

as evidenced by the third experiment. An attempt was made to explain these seemingly conflicting results by appeal to a two-stage model of word recognition whereby frequency plays a role at each stage. This was Forster's (1976) model of lexical access. The two controversial aspects of this model are, first, that lexical access takes the form of an ordered search and, second, that this search takes place in a peripheral file that provides access to a master file where all information is stored.

The most widely accepted alternative model is the logogen model of Morton $(1968,1969)$, as described in the introduction. By this model, stimulus features passively raise the activation level of those logogens (or lexical entries) that correspond to words containing these features. Once a logogen reaches some activation threshold, the word corresponding to it becomes available for recognition. How does the logogen model incorporate the results of the present experiments and also those of Taft (1979) and Taft and Forster (1975, 1976)?

The finding that words are accessed through their stem morphemes (or more precisely, their BOSSs) can be accounted for easily by arguing that the features of the stimulus item that raise the activation level of the logogen for that item are predominantly the features of its stem (or BOSS). But what does it mean for the logogen model to say that words coming from the same stem are accessed through the same entry? What it must mean is that a particular logogen can stand for more than one word, and thus when "reproach" is presented, the word "approach" will also become available for response along with "reproach." Further processing must then be carried out in order for the stimulus item to be recognized as "reproach" rather than "approach," and thus, the logogen model would 
become virtually indistinguishable from the peripheral file/master file model.

It is not the case, however, that the peripheral file/ master file model need necessarily be a search model as opposed to a direct access model. It is possible that the entries in the orthographic file are accessed via a direct look-up system (as Morton, 1968, 1969, proposes). However, a simple direct look-up system has difficulties accounting for interference effects of the sort observed by Taft (1979) and Taft and Forster $(1975,1976)$. For example, it was found by Taft and Forster (1976) that a word that was also the first syllable of another, more frequent, word (e.g., "neigh" from "neighbor") took longer to recognize than a word that was not the first part of another word (e.g., "scoff"). The explanation for this in terms of the search model is that there is an entry "neigh" in the peripheral file for the purpose of recognizing "neighbor" (i.e., its BOSS) and another entry "neigh" for the purpose of recognizing the word "neigh." Recognition times for "neigh" are therefore delayed by the encountering of the inappropriate "nonword" entry "neigh." After this entry has been ascertained to be inappropriate, the search must continue until the correct entry "neigh" is found. How can a direct look-up model account for such an interference effect where, for example, "neighbor" interferes with the recognition of "neigh"? It would have to say that the logogen for "neighbor" reached threshold level, was evaluated, and was found to be inappropriate, and then the logogen for "neigh" reached threshold and was found to be appropriate. In other words, more than one lexical entry would have to be accessed, and furthermore, these entries would have to be accessed in serial order. With this modification, the direct access model now becomes virtually indistinguishable from the search model.

What a logogen system does provide, though, is a possible means of restricting the size of the set of entries that is to be searched in the orthographic file, or, in terms of Rubenstein et al. (1970), a means of "marking off" a subset of the lexicon to be searched. Thus the logogen model and the search model are not incompatible, but rather, can be seen as two stages of the one accessing procedure incorporated within a peripheral file/master file system.

\section{REFERENCES}

Broadbent, D. E. Word-frequency effect and response bias. Psychological Review, 1967, 74, 1-15.
Carroll, J. B., Davies, P., \& Richman, B. The American heritage word frequency book. Boston: Houghton-Mifflin, 1971.

Forster, K. I. Accessing the mental lexicon. In E. C. T. Walker \& R. J. Wales (Eds.), New approaches to language mechanisms. Amsterdam: North-Holland, 1976.

Forster, K. I., \& Bednall, E. S. Terminating and exhaustive search in lexical access. Memory \& Cognition, 1976, 4, 53-61.

Kučera, H., \& Francis, W. N. Computational analysis of present-day American English. Providence, R.I: Brown University Press, 1967.

Manelis, L., \& Tharp, D. A. The processing of affixed words. Memory \& Cognition, 1977, 5, 690-695.

Meyer, D. E., \& Schvaneveidot, R. W. Facilitation in recognizing pairs of words: Evidence of a dependence between retrieval operations. Journal of Experimental Psychology, 1971, 90, 227-234.

Morton, J. Grammar and computation in language behavior. In J. C. Catford (Ed.), Studies in language and language behavior. Center for Research in Language and Language Behavior, Progress Report No. VI. Ann Arbor, Mich: University of Michigan Press, 1968.

Monton, J. Interaction of information in word recognition. $P_{s y-}$ chological Review, 1969, 76, 165-178.

O'CONNOR, R. E. An investigation into the word frequency effect. Unpublished honors thesis, Monash University, 1975.

REISNER, P. Storage and retrieval of polymorphemic words in the internal lexicon. Unpublished PhD thesis, Lehigh University, 1972.

Rosenberg, S., Coyle, P. J., \& Porter, W. L. Recall of adverbs as a function of the frequency of their adjectival roots. Journal of Verbal Learning and Verbal Behavior, 1966, 5, 75-76.

Rubenstein, H., Garfield, L., \& Millikan, J. A. Homographic entries in the internal lexicon. Journal of Verbal Learning and Verbal Behavior, 1970, 9, 487-494.

SwIFT, D. J. The effects of context, word frequency, and internal redundancy in reading and word perception. Unpublished thesis, University of New Hampshire, 1977.

TAFT, M. Lexical access via an orthographic code: The basic orthographic syllabic structure (BOSS). Journal of Verbal Learning and Verbal Behavior, 1979, 18, 21-39.

TAFT, M., \& Forster, K. I. Lexical storage and retrieval of prefixed words. Journal of Verbal Learning and Verbal Behavior, 1975, 14, 638-647.

TAFT, M., \& Forster, K. I. Lexical storage and retrieval of polymorphemic and polysyllabic words. Journal of Verbal Learning and Verbal Behavior, 1976, 15, 607-620.

Thorndike, E. L., \& Lorge, I. The teacher's word book of 30,000 words. New York: Teacher's College, Columbia University, 1944.

\section{NOTE}

1. Note that it was only the lower frequency word containing a particular stem that was used in the experiment. That is, while "reproach" and "dissuade" were experimental items, "approach" and "persuade" were not.

(Received for publication October 6, 1978; revision accepted March 15, 1979.)

\section{Appendix}

Lexical Decision Times for the Items Used in Each Experiment

\begin{tabular}{lllllll} 
& & \multicolumn{2}{c}{ Experiment 1} & & \\
reproach & 720 & dissuade & 810 & relieve & 699 & derive \\
recline & 747 & persecute & 816 & discern & 729 & avail \\
reprise & 756 & reprehend & 897 & aggregation & 820 & incriminate \\
remand & 756 & demote & 859 & detain & 699 & invert \\
perplex & 737 & avenge & 779 & ingest & 744 & pervade \\
leploy & 737 & deflate & 790 & digress & 726 & perjure
\end{tabular}




\begin{tabular}{|c|c|c|c|c|c|c|c|}
\hline $\begin{array}{l}\text { perturb } \\
\text { depreciate } \\
\text { decrease }\end{array}$ & $\begin{array}{l}799 \\
863 \\
717\end{array}$ & $\begin{array}{l}\text { convene } \\
\text { decelerate } \\
\text { convey }\end{array}$ & $\begin{array}{l}878 \\
864 \\
711\end{array}$ & $\begin{array}{l}\text { deduce } \\
\text { constrict } \\
\text { affluence }\end{array}$ & $\begin{array}{l}778 \\
802 \\
693\end{array}$ & $\begin{array}{l}\text { expel } \\
\text { diverge } \\
\text { excise }\end{array}$ & $\begin{array}{l}752 \\
797 \\
793\end{array}$ \\
\hline \multicolumn{8}{|c|}{ Experiment 2: Inflected Words } \\
\hline $\begin{array}{l}\text { sized } \\
\text { humans } \\
\text { fearing } \\
\text { beats } \\
\text { realizes } \\
\text { silenced } \\
\text { blocking } \\
\text { cares } \\
\text { guessing } \\
\text { waters }\end{array}$ & $\begin{array}{l}598 \\
556 \\
578 \\
544 \\
578 \\
576 \\
556 \\
574 \\
574 \\
574\end{array}$ & $\begin{array}{l}\text { raked } \\
\text { patrons } \\
\text { gasping } \\
\text { beads } \\
\text { residues } \\
\text { trembled } \\
\text { fetching } \\
\text { coins } \\
\text { crawling } \\
\text { limits }\end{array}$ & $\begin{array}{l}659 \\
589 \\
660 \\
603 \\
637 \\
598 \\
639 \\
568 \\
644 \\
546\end{array}$ & $\begin{array}{l}\text { keeps } \\
\text { priced } \\
\text { learns } \\
\text { oceans } \\
\text { grouped } \\
\text { moons } \\
\text { timed } \\
\text { lakes } \\
\text { kills } \\
\text { placing }\end{array}$ & $\begin{array}{l}510 \\
544 \\
541 \\
515 \\
595 \\
589 \\
573 \\
580 \\
492 \\
520\end{array}$ & $\begin{array}{l}\text { tales } \\
\text { merged } \\
\text { prints } \\
\text { ounces } \\
\text { roasted } \\
\text { mules } \\
\text { raged } \\
\text { bites } \\
\text { slums } \\
\text { staring }\end{array}$ & $\begin{array}{l}587 \\
640 \\
496 \\
705 \\
551 \\
594 \\
572 \\
560 \\
600 \\
695\end{array}$ \\
\hline \multicolumn{8}{|c|}{ Experiment 2: Uninflected Words } \\
\hline $\begin{array}{l}\text { acre } \\
\text { parent } \\
\text { guest } \\
\text { gather } \\
\text { eye } \\
\text { bruise } \\
\text { chew } \\
\text { crush } \\
\text { troop } \\
\text { nail }\end{array}$ & $\begin{array}{l}571 \\
556 \\
524 \\
545 \\
488 \\
572 \\
620 \\
542 \\
583 \\
534\end{array}$ & $\begin{array}{l}\text { dual } \\
\text { tennis } \\
\text { piano } \\
\text { bundle } \\
\text { bed } \\
\text { twinge } \\
\text { swap } \\
\text { freak } \\
\text { saint } \\
\text { goat }\end{array}$ & $\begin{array}{l}585 \\
524 \\
611 \\
703 \\
494 \\
706 \\
685 \\
574 \\
530 \\
584\end{array}$ & $\begin{array}{l}\text { shoe } \\
\text { excite } \\
\text { mile } \\
\text { obtain } \\
\text { happen } \\
\text { settle } \\
\text { flower } \\
\text { lip } \\
\text { involve } \\
\text { plunge }\end{array}$ & $\begin{array}{l}553 \\
556 \\
579 \\
653 \\
518 \\
564 \\
540 \\
543 \\
582 \\
583\end{array}$ & $\begin{array}{l}\text { fork } \\
\text { aspire } \\
\text { pink } \\
\text { excess } \\
\text { narrow } \\
\text { barrel } \\
\text { genius } \\
\text { pen } \\
\text { decline } \\
\text { sparse }\end{array}$ & $\begin{array}{l}597 \\
625 \\
541 \\
642 \\
639 \\
543 \\
546 \\
478 \\
570 \\
683\end{array}$ \\
\hline \multicolumn{8}{|c|}{ Experiment 3: Inflected Words } \\
\hline $\begin{array}{l}\text { things } \\
\text { boats } \\
\text { pieces } \\
\text { learned } \\
\text { followed } \\
\text { plants } \\
\text { circles } \\
\text { lifted } \\
\text { washing } \\
\text { taxes }\end{array}$ & $\begin{array}{l}468 \\
523 \\
497 \\
513 \\
525 \\
520 \\
485 \\
556 \\
519 \\
577\end{array}$ & $\begin{array}{l}\text { worlds } \\
\text { truths } \\
\text { fronts } \\
\text { classed } \\
\text { numbered } \\
\text { floors } \\
\text { winters } \\
\text { rained } \\
\text { filming } \\
\text { sixes }\end{array}$ & $\begin{array}{l}571 \\
531 \\
606 \\
570 \\
611 \\
498 \\
577 \\
530 \\
552 \\
572\end{array}$ & $\begin{array}{l}\text { smiled } \\
\text { fields } \\
\text { liked } \\
\text { horses } \\
\text { feeling } \\
\text { trying } \\
\text { skills } \\
\text { keys } \\
\text { waves } \\
\text { funds }\end{array}$ & $\begin{array}{l}528 \\
486 \\
533 \\
553 \\
542 \\
545 \\
497 \\
514 \\
614 \\
531\end{array}$ & $\begin{array}{l}\text { sized } \\
\text { deaths } \\
\text { timed } \\
\text { thirds } \\
\text { needing } \\
\text { naming } \\
\text { cleans } \\
\text { suns } \\
\text { heats } \\
\text { lacks }\end{array}$ & $\begin{array}{l}558 \\
522 \\
502 \\
492 \\
593 \\
666 \\
490 \\
596 \\
615 \\
577\end{array}$ \\
\hline \multicolumn{8}{|c|}{ Experiment 3: Uninflected Words } \\
\hline $\begin{array}{l}\text { milk } \\
\text { gold } \\
\text { birth } \\
\text { rear } \\
\text { blood } \\
\text { health } \\
\text { sky } \\
\text { bulk } \\
\text { terror } \\
\text { fat }\end{array}$ & $\begin{array}{l}508 \\
514 \\
492 \\
583 \\
547 \\
538 \\
487 \\
585 \\
568 \\
515\end{array}$ & $\begin{array}{l}\text { acre } \\
\text { hunt } \\
\text { troop } \\
\text { shoe } \\
\text { marry } \\
\text { clothe } \\
\text { nod } \\
\text { chew } \\
\text { mutter } \\
\text { lip }\end{array}$ & $\begin{array}{l}560 \\
554 \\
564 \\
498 \\
587 \\
615 \\
587 \\
538 \\
791 \\
499\end{array}$ & $\begin{array}{l}\text { dinner } \\
\text { unique } \\
\text { rice } \\
\text { fresh } \\
\text { cabbage } \\
\text { tin } \\
\text { dumb } \\
\text { mist } \\
\text { vacuum } \\
\text { cane }\end{array}$ & $\begin{array}{l}533 \\
626 \\
583 \\
505 \\
545 \\
499 \\
571 \\
518 \\
576 \\
533\end{array}$ & $\begin{array}{l}\text { parent } \\
\text { excite } \\
\text { nail } \\
\text { shout } \\
\text { freckle } \\
\text { rib } \\
\text { clap } \\
\text { drip } \\
\text { oblige } \\
\text { poke }\end{array}$ & $\begin{array}{l}547 \\
581 \\
564 \\
590 \\
549 \\
668 \\
540 \\
545 \\
640 \\
612\end{array}$ \\
\hline
\end{tabular}

Note-For Experiments 2 and 3, items are arranged in pairs. For Experiment 2, the higher base frequency words in Columns 1 and 3, respectively, are listed opposite their lower base frequency matches in Columns 2 and 4. For Experiment 3, Columns 1 and 3 contain higher surface frequency words, and the corresponding lower surface frequency words are listed in Columns 2 and 4. 